\title{
PENETRATING EYE INJURIES IN CHILDREN OF THE WEST BANK AND GAZA STRIP
}

\author{
MARK J. ELDER \\ Jerusalem
}

\begin{abstract}
SUMMARY
A retrospective study was carried out on 118 children with penetrating eye injuries. Fifty-three per cent of those without an intraocular foreign body $(50 / 94)$ achieved a final visual acuity of $6 / 12$ or better, whilst $13 \%(14 / 108)$ required an enucleation. Mixed corneoscleral wounds, vitreous haemorrhage and retinal detachment were bad prognostic features. Important principles of management are discussed.
\end{abstract}

Penetrating eye injuries in children are a serious and demanding ophthalmic problem, often complicated by difficulties in clinical examination and a tendency to amblyopia from multiple aetiologies. These injuries constitute between $9 \%$ and $48 \%$ of all ocular trauma to children,${ }^{1-7}$ while childhood ocular trauma in turn accounts for between $27 \%$ and $52 \%$ of all ocular trauma. ${ }^{4,8-13}$ This study looks at 118 children with perforating injuries from the West Bank and Gaza strip.

\section{PATIENTS AND METHODS}

A retrospective study was undertaken on all children with a penetrating eye injury presenting to the St. John Ophthalmic Hospital, Jerusalem, within the 2-year period January 1988 to December 1989. The review was undertaken 2 years after the end of the study period, in January 1992, to allow sufficient time for any late complications to appear. Case records were retrieved for 118 of 121 children. No case was excluded from the study.

Presentation was within 24 hours of the injury in 106 cases. Surgical repair was effected with the patient under general anaesthesia and using an operating microscope in all cases; all corneal wounds except one were sutured with $10 / 0$ nylon. Iris prolapse was completely reposited in 61 of 68 cases. Lens capsule rupture apparent at the time of initial repair was treated by lensectomy or extracapsular cataract extraction at that stage. All patients received subconjunctival antibiotics, usually $20 \mathrm{mg}$ gentamycin. Enuc-

From: St. John Ophthalmic Hospital, PO Box 19960, Jerusalem, Israel.

Correspondence to: Mr. Mark J. Elder, 1 Grosvenor Crescent, London SW1, UK. leation was not performed as a primary procedure unless it was considered that the eye was irreparably damaged.

Follow-up time ranged from 1.8 to 4.0 years with a mean of 3.2 years. Follow-up was unsatisfactory in 10 patients: 7 with purely corneal wounds, 2 with mixed wounds and 1 with an intraocular foreign body (IOFB). These cases are excluded from the tables on final outcome.

\section{RESULTS}

The mean age of the patients was $8.2 \pm 5.1$ years (range from 6 months to 17 years). There were only two 17 -yearolds and four 16-year-olds in the study group. The 15 patients with retained IOFBs had a mean age of $11.9 \pm 3.4$ years (range 5-16 years).

The aetiology of the injuries is summarised in Table I. Sixteen injuries (14\%) were due to the military occupation of the area and $7(6 \%)$ resulted from the children working.

\section{Penetrating Injury Without IOFB}

One hundred and three children (mean age $7.6 \pm 5.0$ years) had a penetrating injury withou an IOFB. The types of wounds are summarised in Table II and their respective visual outcomes outlined in Table III. Immediate com-

Table I. Aetiology of the penetrating injury

\begin{tabular}{lc}
\hline Fall & 17 \\
Flying glass & 15 \\
Thrown stone & 15 \\
Wood (play) & 14 \\
Rubber bullet & 10 \\
Metal (play) (wark-related) & 9 \\
Hammering (work & 7 \\
Knife (accidental) & 6 \\
Scissors & 4 \\
Bottle top & 3 \\
Field mine & 2 \\
Explosives (play) & 2 \\
Road traffic accident & 2 \\
Fork/spoon & 2 \\
Toothbrush & 1 \\
Exploding television & 1 \\
Chicken peck & 1 \\
Plastic bullet & 1 \\
Unknown & 6 \\
Total & 118 \\
\hline
\end{tabular}


Table II. Types of penetrating wound (no IOFB)

\begin{tabular}{lrr}
\hline Corneal & 61 & $(59 \%)$ \\
Limbal & 2 & $(2 \%)$ \\
Scleral & 12 & $(12 \%)$ \\
Mixed & 28 & $(27 \%)$ \\
Total & $103(100 \%)$ \\
\hline
\end{tabular}

Table III. Final visual outcome in relation to wound type (no IOFB)

\begin{tabular}{lrrrr}
\hline & \multicolumn{4}{c}{ Wound type } \\
\cline { 2 - 5 } Visual acuity & Corneal & Limbal & Scleral & Mixed \\
\hline $6 / 12+$ & $34(63 \%)$ & 1 & $7(58 \%)$ & $8(31 \%)$ \\
$6 / 18-6 / 36$ & $6(11 \%)$ & - & - & $1(4 \%)$ \\
$6 / 60-P L$ & $9(17 \%)$ & 1 & $1(8 \%)$ & $4(15 \%)$ \\
NPL & $4(7 \%)$ & - & $4(33 \%)$ & $4(15 \%)$ \\
Enucleation & $1(2 \%)$ & - & - & $9(35 \%)$ \\
Total & 54 & 2 & 12 & 26 \\
\hline
\end{tabular}

PL, perception of light; NPL, no perception of light.

plicating factors, defined as those factors at the time of the initial examination and primary surgical repair, are listed in Table IV. There was no statistically significant difference (chi-squared test, $p=0.05$ ) between the final visual acuity of those patients who had only a full-thickness wound compared with those who had either iris prolapse, lens trauma or vitreous loss. But the patients in whom iris prolapse, lens trauma and vitreous loss were all present at initial presentaion were less likely to achieve a final visual acuity of $6 / 12$ or better (chi-squared test, $0.01>p>$ 0.001 ). Similarly, patients with mixed corneoscleral wounds were less likely to achieve a final acuity of $6 / 12$ or better $(0.05>p>0.02)$ and were more likely than those with other wound types to have a final outcome of either no perception of light or enucleation $(p<0.001)$.

Vitreous haemorrhage was initially present in 23 patients. Only 1 of these attained a final acuity of $6 / 12$ or better, 3 had a final acuity of between $6 / 60$ and perception of light ( 2 had retinal detachment, 1 had macular scarring) and 19 had no perception of light at the time of review (see below).

The late complications are reported in Table V. The patients who developed amblyopia were younger (mean age 3.4 years, range $1-6$ years) than those who did not and represented 23\% (11/47) of the children under the age of 7 years. All patients developing amblyopia had a combination of anisometropic astigmatism and corneal scarring. Of the 7 patients who received occlusion, 3 improved their

Table IV. Immediate complicating factors of trauma (no IOFB)

\begin{tabular}{lcc}
\hline Complicating factors & Total no. & $\begin{array}{c}\text { Visual acuity } \\
6 / 12+\end{array}$ \\
\hline Full-thickness wound only & 20 & $13(65 \%)$ \\
Wound with iris prolapse & 32 & $21(66 \%)$ \\
Wound with lens trauma & 7 & $5(71 \%)$ \\
Wound with vitreous loss & 5 & $4(80 \%)$ \\
Wound with iris prolapse + lens trauma & 12 & $4(33 \%)$ \\
Wound with iris prolapse + lens trauma & & $3(17 \%)$ \\
$\quad+$ vitreous loss & 18 & $30(53 \%)$ \\
Total & 94 & 50 \\
\hline
\end{tabular}

visual acuity to $6 / 12$ or better and maintained it at that level.

Retinal detachment was diagnosed in 19 cases after discharge from hospital. Twelve of these had no perception of light at the time of review. Of the 7 patients with retinal detachment who retained vision, 1 had a localised traction detachment directly over the site of the trauma that did not progress, 1 had a giant retinal tear and 5 developed proliferative vitreoretinopathy (PVR) with open funnel detachment. Six of these patients went on to pars plana vitrectomy and retinal detachment repair; 2 achieved a final visual acuity of 6/12,1 saw $6 / 24$ and 4 had a visual acuity of between $6 / 60$ and counting fingers. Retinal detachment surgery was not performed in 7 of the 12 cases because either the eye had no perception of light or it was thought that surgery would not improve the vision. All the remaining 5 patients who did have retinal detachment surgery but eventually had no perception of light, developed a secondary vitreous haemorrhage at the time of the operation. In these 5 cases surgery was performed within 15 days of the original trauma.

Of the total of 27 patients who developed a retinal detachment $(27 / 94 ; 29 \%)$, 1 had a giant retinal tear, 1 had a localised area of PVR over the site of the trauma, 9 had rhegmatogenous retinal detachment and 16 had fourquadrant PVR. Only the localised PVR and 3 of the cases of rhegmatogenous detachment could be attributed directly to the penetrating injury or wound; the remainder were due to concussive effects causing either retinal tears or vitreous haemorrhage remote from the site of trauma.

Nine patients developed cataract that required secondary surgery. Seven had a lensectomy and 2 had extracapsular cataract extraction and posterior chamber intraocular lenses. All 9 patients saw $6 / 12$ or better with correction.

Twenty-two patients had eyes with no perception of light. Twelve of these patients retained the eye (5 with phthisis bulbi), 6 had a primary enucleation and 4 patients had a secondary enucleation. There were 20 retinal detachments in this group, 8 of which were apparent during the initial hospital admission and 12 which were diagnosed after discharge. The 19 cases of vitreous haemorrhage in these patients were all present at initial presentation.

\section{Penetrating Injury with IOFB}

Fifteen patients had a penetrating injury with an IOFB. The aetiologies and types of foreign body are given in Tables VI and VII respectively. Eighty per cent of the

Table V. Late complications (no IOFB)

\begin{tabular}{lc}
\hline Retinal detachment & 19 \\
Amblyopia & 11 \\
Cataract & 9 \\
Glaucoma & 2 \\
Requiring penetrating keratoplasty & 2 \\
Sympathetic ophthalmia & 1 \\
Infection & 0 \\
Total & $44 / 94(47 \%)$ \\
\hline
\end{tabular}


Table VI. Aetiology of IOFB

\begin{tabular}{lc}
\hline Hammering (work-related) & 5 \\
Land mine & 2 \\
Bullet wound & 2 \\
Playing with explosives & 1 \\
Stone thrown at window & 1 \\
Fall & 1 \\
Flying chip of pottery & 1 \\
Unknown & 2 \\
Total & 15 \\
\hline
\end{tabular}

foreign bodies were non-magnetic and 3 patients had multiple foreign bodies.

The location of the entry wound was corneal in 8 cases, corneoscleral in 5, limbal in 1 and scleral in 1 . The final position of the foreign body was in the anterior segment in 7 cases, the posterior segment in 7 and orbital in 1 (through-and-through injury). The final visual outcomes of the cases are summarised in Table VIII. Enucleation was performed as a primary procedure in 3 patients injured by rubber bullets or thrown stones because the eyes were so badly damaged.

One case of sympathetic ophthalmia developed in a 10year-old with a peripheral corneal wound from a magnetic foreign body located on the macula. The patient had presented with a painful, red ipsilateral eye and hypopyon but with an uncertain history of at least 3 days. The IOFB was removed via the pars plana the following day. The contralateral eye developed severe granulomatous anterior and posterior uveitis 2 weeks after presentation. Oral steroids were required for 4 months and subsequently the final visual acuities were counting fingers and 6/6.

\section{Penetrating Injuries from Rubber Bullets}

Ten patients received penetrating injuries from rubber bullets; one further patient was similarly injured by a fragment of plastic bullet. The mean age of these children was 11.1 years (range 3-17 years). Nine of these 11 patients eventually had no perception of light. Of these, 6 eyes were so badly damaged that they were enucleated as a primary procedure, 2 required secondary enucleation and 1 became phthisical. Only 2 of the 11 eyes retained vision, with one seeing hand movements and the other having a visual acuity of 6/9. In the latter eye a fragment of plastic bullet had caused a simple $8 \mathrm{~mm}$ corneal laceration.

\section{DISCUSSION}

The differences between this study and similar studies in other countries reflect the society in which these children live. All of the children were Palestinian Arabs living in the West Bank and Gaza strip. In general the children

Table VII. Types of IOFB

\begin{tabular}{lc}
\hline Metal, non-magnetic & 6 \\
Metal, magnetic & 3 \\
Ceramic or stone & 4 \\
Glass & 1 \\
Rubber bullet & 1 \\
Total & 15 \\
\hline
\end{tabular}

Table VIII. Final visual acuity in relation to location of IOFB

\begin{tabular}{lcc}
\hline & \multicolumn{2}{c}{ Location of IOFB } \\
\cline { 2 - 3 } Visual acuity & Anterior segment & Posterior segment \\
\hline $6 / 12+$ & 5 & 1 \\
$6 / 18-6 / 36$ & 1 & - \\
$6 / 60-P L$ & - & 2 \\
NPL or enucleation & 1 & 4 \\
Total & 7 & 7 \\
\hline
\end{tabular}

PL, perception of light; NPL, no perception of light.

receive less parental supervision compared with Western societies due to a combination of parental attitudes, large families (typically 6 to 8 children per family) and reduced number of school days. The families are poor and less able to provide toys or sports equipment. In addition the territories have been under military occupation since 1967. It is apparent that no injury was caused by toys (compared with $20 \%$ in one series ${ }^{10}$ ), no injury caused by organised sport, $6 \%$ were caused by children working and $14 \%$ were due to the military occupation.

St. John Ophthalmic Hospital is the major facility within the West Bank and Gaza strip that offers intraocular surgery under general anaesthesia. It is estimated that the hospital treats $75 \%$ of all penetrating injuries within the territories, and therefore the total incidence of such injuries can be calculated as 4.0 per 100000 people per year. This compares with 3.6 in Israel,,${ }^{14} 1.8-3.0$ in Northern Ireland ${ }^{10,11}$ and 0.2 in Wisconsin, USA. ${ }^{15}$

The final visual acuity achieved was $6 / 12$ or better in 50 of 94 patients (53\%) without an IOFB, which is similar to the results of the large published series in adults: $42 \%,{ }^{10}$ $45 \%,{ }^{8} 60 \%,{ }^{16} 62 \% .^{17}$ Only 10 of 94 patients without an IOFB and 4 of 14 patients with an IOFB required enucleation. This total of $13 \%(14 / 108)$ compares favourably with the figures in adults of $21-28 \%,{ }^{8,10,16}$ despite the fact that there was only 1 case of sympathetic ophthalmia and that 8 enucleations were a result of injuries from rubber bullets. These bullets are used as a means of crowd control, weigh $25 \mathrm{~g}$ and are fired with a muzzle velocity of $240 \mathrm{~m} / \mathrm{s}$ which is sufficient to penetrate the skull.

Corneoscleral wounds have a worse prognosis in terms of final visual function, as do the immediate complicating factors of iris prolapse, lens damage and vitreous loss combined. Vitreous haemorrhage at initial presentation has a very poor prognosis. ${ }^{16}$ This is also true of retinal detachment, which is common, may be of multiple types and may appear early or late. Examining the posterior segment including the retinal periphery is difficult in children, particularly those with anterior segment damage, but is very important in these cases and examination under anaesthetic may at times be required. Previously, injury to the lens was a 'grave incident' ${ }^{16}$ but this was not the case in this study or in other recent studies ${ }^{17,18}$ where prompt secondary lensectomy or cataract extraction was performed.

In conclusion, prompt surgical attention to penetrating eye injuries without an IOFB allowed the achievement of a 
visual acuity of $6 / 12$ or better in $53 \%$ of these children. Trauma sufficient to penetrate the globe may also cause serious concussive effects on the posterior segment. Postoperatively, vigilance for refractive errors, amblyopia and retinal tears is essential and orthoptic assessment may be invaluable in distinguishing amblyopia from poor vision due to anterior segment abnormalities.

Key words: Eye injuries, Intraocular foreign bodies, Penetrating eye injuries, Retinal detachment, Trauma.

\section{REFERENCES}

1. Niiranen M, Raivio I. Eyẹ injuries in children. Br J Ophthalmol 1981;65:436-8.

2. Moreira CA, Debert-Ribeiro M, Belfort R. Epidemiological study of eye injuries in Brazilian children. Arch Ophthalmol 1988;106:781-4.

3. Lambah P. Some common causes of eye injury in the young. Lancet 1962;2:1351-3.

4. Rapoport I, Romen M, Kinek M, Teller J, Belkin M, Yelin $\mathrm{M}$, Savir H. Eye injuries in children in Israel: a nationwide collaborative study. Arch Ophthalmol 1990;108:376-9.

5. Holland G. Augen- und Lidverletzungen im Kindersalter. Klin Monatsbl Augenheilkd 1961;139:72-82.

6. Kobor J. Augenverletzungen des Kindersalter. Klin Monatsbl Augenheilkd 1965;146:740-54.
7. Sollner F. Über Augenverletzungen in Kindersalter und ihre Verhutung. J Optalmol Soc 1966;37:47-88.

8. Roper-Hall MJ. The treatment of ocular injuries. Trans Ophthalmol Soc UK 1959;79:57-69.

9. Ilsar M, Chirambo M, Belkin M. Ocular injuries in Malawi. Br J Ophthalmol 1982;66:145-8.

10. Johnston S. Perforating eye injuries: a five year survey. Trans Ophthalmol Soc UK 1971;91:895-921.

11. Canavan YM, O'Flaherty MJ, Archer DB, Elwood JH. A 10-year survey of eye injuries in Northem Ireland 19671976. Br J Ophthalmol 1980;64:618-25.

12. Maltzman BA, Pruzon H, Mund ML. A survey of ocular trauma. Surv Ophthalmol 1976;21:285-90.

13. Thordarson U, Ragnarso AT, Gunbrandsson B. Ocular trauma: observations in 105 patients. Acta Ophthalmol (Copenh) 1976;57:922-8.

14. Koval R, Teller J, Belkin M, Romem M, Yanko L, Savir H. The Israel ocular injuries study: a nationwide collaborative study. Arch Ophthalmol 1986;104:776-80.

15. Karlson TA, Klein BEK. The incidence of acute hospitaltreated eye injuries. Arch Ophthalmol 1986;104:1473-6.

16. Duke-Elder WS. System of ophthalmology. Vol. XIV. London: Kimpton, 1972:421.

17. Eagling EM. Perforating injuries of the eye. Br J Ophthalmol 1976;60:732-6.

18. Eagling EM. Perforating injuries involving the posterior segment. Trans Ophthalmol Soc UK 1975;95:335-9. 